\title{
TUTELA PROVISÓRIA SATISFATIVA NAS CONTRARRAZÕES RECURSAIS
}

\author{
Francisco Silveira de Aguiar Neto ${ }^{1}$ \\ https://orcid.org/0000-0003-4874-6269 \\ Fabio Rychecki Hecktheuer ${ }^{2}$ \\ http://orcid.org/0000-0001-9171-3740 \\ Recebido em: 15 jun. 2020 \\ Aceito em: 18 ago. 2020
}

Como citar este artigo: NETO, Francisco Silveira de Aguiar; HECKTHEUER, Fabio Rychecki. TUTELA PROVISÓRIA SATISFATIVA NAS CONTRARRAZÕES RECURSAIS. Revista Visão: Gestão Organizacional, Caçador, SC, Brasil, v. 9, n. 2, p. 55-72, jul./dez. 2020. Disponível em: http://dx.doi.org/10.33362/visao.v9i2.2297

Resumo: O presente trabalho tem como propósito estudar a regulamentação da tutela provisória no âmbito das contrarrazões recursais de acordo com o CPC/2015, buscando sistematizá-la à luz da legislação, da jurisprudência e da doutrina, além de tratar de algumas controvérsias e particularidades sobre o assunto.

Palavras-Chave: Tutela Provisória. Recursos. Efeitos dos Recursos. Contrarrazões. Igualdade Processual.

\section{PROVISIONAL PROTECTION IN THE CONTEXT OF COUNTERARGUMENTS IN APPEALS}

Abstract: The purpose of this paper is to study the regulation of provisional protection in the context of counterarguments in appeals according to the Brazilian Civil Procedure Code of 2015, seeking to systematize it in the light of legislation, jurisprudence and doctrine, in addition to addressing some controversies and particularities about the subject.

Keywords: Provisional Protection. Appeals. Effects of Appeals. Counterarguments. Procedural Equality.

\section{INTRODUÇÃO}

A Tutela Provisória Satisfativa se apresenta como um instituto jurídico disposto a redistribuir o ônus do tempo do processo ao antecipar os efeitos da decisão de mérito antes

\footnotetext{
${ }^{1}$ Procurador do Estado de Rondônia. Graduado em Direito pela Universidade de Fortaleza. Pós-Graduado 'lato sensu' em Direito Processual Civil pela Pontifícia Universidade Católica de São Paulo. Mestrando em Direito Processual Civil pela Pontifícia Universidade Católica de São Paulo. E-mail: franciscoaguiar@pge.ro.gov.br.

2 Pós-doutorado em Psicologia da Aprendizagem pela Universidad Autonoma de Madrid (UAM); Doutor pela Universidad Autonoma de Madrid (UAM), com título apostilado pela Universidade Federal do Rio Grande do Sul (UFRGS). Professor dos Programas de Pós-Graduação em: Ciência Política da Universidade Federal do Rio Grande do Sul (UFRGS), Universidade do Vale do Itajaí (UNIVALI). Reitor da Faculdade Católica de Rondônia. E-mail: fabioheck@fcr.edu.br.
} 
do fim do processo. Técnicas processuais que busquem garantir a tutela específica são essenciais para que o Poder Judiciário possa ser um meio de se concretizar os direitos e não apenas a transmutação dos direitos em indenizações.

A antecipação já virou prática comum na atividade forense. Durante o sistema vigente no CPC/1973, era lugar comum encarar a Tutela Antecipada como algo a ser tratado apenas no início da relação processual. No máximo, a mesma teria que ser resolvida antes ou durante a sentença.

Como será explicado, o consumidor de serviços jurisdicionais poderá perfeitamente ter a necessidade, assim como alcançar as condicionantes legais deste instrumento, apenas na fase recursal do processo. A prática forense demonstra que a utilidade de tal antecipação não se esvai com a prolação da sentença, sendo possível que seja ainda mais necessária durante a fase recursal.

Como já dito, no digesto processual revogado, a antecipação de tutela era tratada principalmente como matéria do primeiro grau de juízo. Mesmo com a previsão do art. 558 do diploma revogado, não era comum a busca por este tipo de tutela provisória no âmbito da apelação.

O CPC/2015 trouxe interessante inovação nesta matéria ao prever expressamente em seu art. 932, II, a possibilidade de ser analisado o pedido de tutela provisória no âmbito recursal. Ainda que a redação seja um tanto sucinta, resta claro a ampla possibilidade de concessão de tutela provisória satisfativa neste âmbito.

Este trabalho tem como rota o estudo da tutela provisória satisfativa na fase recursal. O diploma processual vigente prevê expressamente essa possibilidade. Todavia, entendemos relevante estudar os limites de tal dispositivo. Na presente análise, focaremos na possibilidade de o polo passivo do recurso se utilizar de tal provimento. A ideia pode parecer contra intuitiva, vez que tal pedido é normalmente associado com o polo ativo da ação. Entretanto, não podemos ignorar tal cenário, e sua eventual utilidade, o que clama a devida análise.

O modelo constitucional do processual impõe a interpretação dos institutos processuais de acordo com os princípios constitucionais, sendo relevante no caso o da igualdade e o da eficácia. Sob este prisma, iremos analisar se a falta de previsão legal permite a intepretação de que seria possível o pedido de tutela provisória nas contrarrazões.

O faremos com base principalmente na ampla doutrina sobre o assunto, mas também analisando a jurisprudência sobre o assunto.

\section{A TUTELA PROVISÓRIA SATISFATIVA}

A Antecipação de Tutela é uma ferramenta processual cujo propósito é a distribuição do ônus do tempo do processo por meio da concessão do pedido mediato, ou parte dele, à 
parte. Portanto, é um instrumento de grande valia do dia-a-dia forense, sendo de comum uso. Não é exagero dizer que em muitas lides estão as partes mais interessadas na concessão de tutela provisória do que na decisão de mérito final.

Entre as previsões da codificação processual vigente é possível, inclusive, que a lide seja resolvida apenas com a tutela provisória satisfativa antecedente. Trata-se do caso de estabilização de tutela. Portanto, resta claro a enorme importância que tal instituto possui.

Para que possamos analisar sua aplicabilidade no âmbito recursal, imprescindível buscar primeiro compreender de forma ampla o instituto.

\section{DA DEFINIÇÃO DE TUTELA ANTECIPADA}

Uma constante no estudo do direito processual é a busca de soluções para o eterno problema da demora excessiva para a conclusão do processo. O uso de provimentos cautelares, desde muito, era a primeira forma de se buscar combater tais problemas. Com o desenvolver da ciência processual, novas formas de enfrentar este mal foram desenvolvidas. Uma destas é a tutela antecipada.

Antes de sua introdução no ordenamento, era corriqueira a prática de se pleitear medidas cautelares de cunho satisfativo, com inspiração na doutrina italiana, com o objetivo de obter o pedido mediato em momento anterior ao da sentença. Tal prática criava uma confusão entre medidas cautelares e antecipatórias que deve ser evitada.

$\mathrm{Na}$ égide do CPC/2015, a união de medidas cautelares e antecipatórias levou a uma certa confusão entre os dois institutos. Todavia, não obstante o tratamento em conjunto destas ferramentas, assim como a possibilidade da confusão destes em alguns casos extremos, não se pode chegar ao ponto de declarar que não haveria mais diferença entre estes.

A Tutela Antecipada, apesar de possuir pontos em comuns com a Cautelar, apresentase como uma diferente ferramenta para defender a efetividade do processo. Apesar das aparências, destacam-se as diferenças entre os institutos.

Ainda com as mudanças proporcionadas pelo CPC/2015, não há que se imaginar que as barreiras entre a tutela antecipada e cautelar tenham sido derrubadas. A tutela antecipada busca redistribuir o ônus do tempo do processo. Como se sabe, mesmo o processo mais célere, contanto que seja justo, requer uma certa medida de tempo para sua conclusão. Em regra, cabe a parte pleiteante arcar com os custos decorrentes dessa espera.

Se, ao final, restar comprovado que esta possuía a razão sobre a questão, não seria injusto ter a parte que arcar com tais custos. O objetivo da tutela antecipada é permitir que, alcançados os requisitos legais, tal ônus seja redistribuído ${ }^{3}$. Permitindo-se que o pedido

\footnotetext{
${ }^{3}$ ZAVASCKY, Teori Albino. Antecipação da Tutela. São Paulo: Saraiva, 1997. p. 46.
} 
mediato da parte seja transmitido para o pleiteante.

Por sua vez, a tutela cautelar busca impedir que este ônus do tempo acabe por tornar inviável a concessão do bem da vida discutido. O propósito nesta é a preservação. Ainda que seja inevitável a ocorrência de casos limítrofes onde não seja possível distinguir entre ambas as tutelas, isso não justifica o afastamento das diferenças entre ambas.

O novel art. 300 do CPC/2015 coloca dois requisitos para a concessão de tutela de urgência, a probabilidade do direito e o perigo de dano ou o risco ao resultado útil do processo. Este dispositivo é constituído de conceitos indeterminados, cabendo ao aplicador do direito procurar no caso concreto se as circunstâncias podem ser enquadradas. Neste sentido tem se o magistério de João Batista Lopes ${ }^{4}$ :

\footnotetext{
Os conceitos indeterminados, como o próprio nome está a indicar, são os que não possuem conteúdo perfeitamente definido ou delimitado e, por isso, ficam na dependência de interpretação flexível do juiz, ajustada à natureza das coisas, segundos as circunstâncias do caso concreto.

[...]

Não há critérios rígidos para determinação do conteúdo dessa expressão, devendo o juiz guiar-se pela máximas de experiência, pelo bom senso e pela eqüidade.
}

Resta claro que a redação do artigo não buscou fazer diferenciação entre a tutela antecipada e a tutela cautelar. Podendo levar a interpretação de que não haveria mais razão de ser na diferença entre estas.

Ocorre que tal linha de pensamento cria outro problema a ser confrontado. Se não existem diferença entre os requisitos, como haveria de o Estado-Juiz decidir entre a concessão de uma tutela ou outra? Não havendo diferença entre os requisitos, a decisão caberia unicamente ao magistrado ou ao pleiteante? Quanto ao réu, não teria este direito a medida menos invasiva?

A suposição de que os requisitos seriam os mesmos para ambas as medidas cria a problemática maior de decidir qual delas seria aplicável a cada caso. Indagação esta que não possui resposta clara e franca. A melhor resposta, a nosso ver, é que, apesar da redação do art. 300 , ainda existe clara diferença entre os requisitos para a concessão de cada uma das tutelas.

Tal diferenciação se concentra no requisito de probabilidade. A probabilidade do direito não pode ser considerado um requisito estático que se satisfaz em um simples critério de tudo ou nada. Probabilidade, por sua própria definição, pode ser alcançado por diferentes níveis. De acordo com Malatesta:

Existindo na noção da probabilidade motivos convergente e divergentes, que são levados em conta, à medida que crescem os motivos convergentes, e diminuem os divergentes, cresce a probabilidade; e vice-versa, à medida que diminuem os motivos convergentes e crescem os divergentes, diminui a probabilidade. [...]

\footnotetext{
${ }^{4}$ LOPES, João Batista. Tutela Antecipada no Processo Civil Brasileiro. 4. ed. São Paulo: Revista dos Tribunais, 2009. p. 98.
} 
Portanto a probabilidade é graduável. Mas não se pode determinar a graduação com termos fixos, pois que o número dos motivos que em abstrato podem vir a influir nela é indefinido; e quanto aos motivos que, em concreto, são levados em conta, existe sempre neles, em primeiro lugar, algo indeterminado que foge à adição numérica, e também, não é simplesmente o número dos motivos que determina o grau da probabilidade, mas especialmente a sua importância, valor lógico que não se pode determinar aritmeticamente. ${ }^{5}$

Portanto a probabilidade do direito não é um requisito estanque, possuindo diferentes níveis. Uma vez que a concessão de tutela antecipada irá afetar em grau superior o demandado, é razoável que a probabilidade do direito exigida neste caso seja mais forte do que no caso do pedido cautelar.

Ignorar tal cenário seria considerar que se trataria de os mesmos requisitos, independente se tratar do provimento cautelar ou satisfativo. Ou seja, a questão se resolveria simplesmente quanto a existência ou não da probabilidade da causa. Qualquer jurista que tenha analisado casos práticos já se deparou com pleitos mais fortes e menos fortes, com as devidas nuanças e escalas entre estes.

O caso pode se aproximar de precedente já firmado em tribunais, pode ser uma causa relativamente nova sem maiores discussões nos tribunais. O material probatório já juntado com a inicial pode ser amplo ou necessitar de maiores dilações. E entre extremos, pode existir milhares de possíveis situações. Logo, não faz sentido se imaginar que a probabilidade do direito da parte possa ser definida sem se considerar o grau.

Havendo diferentes graus, é plenamente natural que se exija a maior probabilidade para o provimento que causa maior distúrbio na realidade fática, que seja, a tutela provisória. Da mesma forma, para a concessão de provimento cautelar, a análise da probabilidade não deverá ser tão aguçada.

O outro requisito é o do risco ao resultado útil do processo. Trata-se do já conhecido periculum in mora. Trata-se da questão do ônus do tempo do processo. Em regra, cabe ao autor suportar este, porém, em casos que o tempo necessário para a conclusão do processo acabe por colocar em risco a própria efetividade da justiça, necessário que se redistribua esse ônus para se garantir o direito das partes. Afinal, justiça tardia não é justiça.

Após passarmos das condições necessárias faz-se necessário analisar os requisitos negativos. As circunstâncias que impedem o provimento, em especial, o perigo de irreversibilidade.

O §3 o art. 300 proíbe a concessão desta ferramenta processual nos casos em que a concessão ocasionar perigo de irreversibilidade. Ressalve-se que a antecipação da tutela é, por natureza, precária, com exceção de quando esta for estabilizada. Logo, caso ela origine um

\footnotetext{
${ }^{5}$ MALATESTA, Nicola Framarino dei. A lógica das provas em matéria criminal. Vol. I. São Paulo: Saraiva, 1960. p. 68.
} 
quadro que impeça o retorno ao status quo ante, a legislação não a permite.

Inicialmente, considere-se que tal proibição não pode ser levada ao extremo de que em todo e qualquer caso em que haja possível irreversibilidade da tutela antecipada esta não deva ser concedida. Ora, a tutela antecipada é avaliada sob uma perspectiva de verossimilhança, pela qual se pode afirmar a probabilidade de procedência do direito autoral. Seguindo este parágrafo, estar-se-ia protegendo um direito improvável às custas de um provável. Tal situação é contrária a própria lógica e ao bom senso que o julgador deve ter diante de qualquer demanda.

Logo, em casos que seja manifesto o direito do autor, mas a concessão da medida antecipatória resulte em um provimento irreversível, faz-se necessário se aplicar os princípios da proporcionalidade e do contraditório. O Princípio da Proporcionalidade determina que o agente público, neste caso o juiz, quando se deparar de uma situação fática que exija sua ação, deve proceder de forma ponderada e racional de acordo com o caso. Quanto a sua aplicação:

\begin{abstract}
Portanto, a doutrina constitucional mais moderna enfatiza que, em se tratando de imposição de restrições a determinados direitos, deve-se indagar não apenas sobre a admissibilidade constitucional da restrição eventualmente fixada (reserva legal), mas também sobre a compatibilidade das restrições estabelecidas com o princípio da proporcionalidade. (Grifos no Original) ${ }^{6}$
\end{abstract}

A aplicação da proporcionalidade depende do uso dos subprincípios da adequação, necessidade e proporcionalidade em sentido estrito. A medida deve ser adequada para fazer frente a situação, necessária, não meramente vantajosa e proporcional, do ponto de vista de limitar a infração do direito outro ao mínimo possível.

No âmbito do Processo Civil tal diretriz deve ser seguida, tendo em vista a possibilidade de limitações a efetividade do processo que não se justifiquem em um certo quadro. Mesmo normas legais devem seguir a regra da proporcionalidade, sob pena de afrontarem a própria constituição. O Supremo, ainda que no regime constitucional anterior, já se posicionou neste sentido, em referência a normas restritivas de direitos ${ }^{7}$.

Tal ponderação entre as situações fáticas a fim de garantir uma solução justa e razoável é uma manifestação do Devido Processo Legal Substancial, que pode ser considerado a fonte da qual emana o Princípio da Proporcionalidade. Por meio deste conceito, o devido processo legal não pode se resumir a garantia do contraditório e ampla defesa, mas deve também garantir um julgamento justo e efetivo.

Por sua vez, o Princípio do Contraditório determina que todo processo deve transcorrer de forma a permitir que ambas as partes sejam ouvidas e influam na decisão

\footnotetext{
${ }^{6}$ MENDES, Gilmar Ferreira. BRANCO, Paulo Gustavo Gonet. Curso de Direito Consitucional. 6. ed. São Paulo: Saraiva, 2011. p. 256.

${ }^{7}$ GRINOVER, Ada Pellegrini. O Controle de Políticas Públicas pelo Judiciário. Revista de Processo. v. 164, p. 9, out. 2008.
} 
jurisdicional. Sobre esse diapasão não pode o julgador se escusar de conceder um provimento antecipatório irreversível quando uma parte apresenta matéria probatória robusta e a outra não o faz.

Deste modo, a tutela antecipada é uma ferramenta processual com o intuito de redistribuir o ônus do tempo do processo, contanto que sejam atendidos os seus requisitos legais. Ademais, as limitações legais a sua concessão podem, e devem, ser afastadas de acordo com a aplicação do princípio da proporcionalidade e a análise do caso concreto.

\title{
DA LEGITIMIDADE PARA O PLEITO DA TUTELA ANTECIPADA
}

Muito foi dito nas linhas acima sobre a possibilidade de concessão da tutela antecipada no âmbito do Processo Civil. Como se é de imaginar, o foco do estudo coloca como a parte interessada no provimento o autor. Nada mais natural, vez que este busca a tutela judicial a fim de alterar eventual situação.

Ocorre que isto não quer dizer que tal ferramenta cabe unicamente ao autor da ação. Ainda que seja difícil de imaginar eventual exemplo, a norma em nenhum momento impede que a parte ré na relação processual faça uso do instituto. Como exposto acima, o princípio do contraditório garante que ambas as partes possam ser ouvidas e apreciadas pela autoridade jurisdicional.

Paralelo a esse princípio, há o da paridade de armas. Por meio deste, busca-se alcançar a igualdade real entre as partes, não meramente formal. Portanto, seria contrário aos próprios princípios basilares que regem o processo a proibição do uso das tutelas provisórias por parte do réu. Citemos a doutrina:

\begin{abstract}
A questão passa pela seguinte pergunta: qual a tutela jurisdicional que pretende o réu nessa situação? Como o réu não teria um pedido próprio de tutela jurisdicional, a proteção que ele iria pretender obter do Judiciário seria a negativa do pleito do autor. É claro que essa proteção, integralmente considerada, não poderia ser antecipada, pois dependeria do julgamento do mérito e trânsito em julgado. Mas o caso é semelhante ao já tratado anteriormente, da antecipação de tutela em ações declaratórias. A certeza jurídica não poderia ser antecipada, mas alguns dos efeitos daquela declaração, sim. ${ }^{8}$
\end{abstract}

Portanto, o fato de ser difícil imaginar um caso em que haja interesse, ou possibilidade, de o réu requerer a concessão de tutela antecipada, não torna contrário a norma eventual pedido. Deste modo, tanto o polo ativo quanto o passivo podem se valer da tutela antecipada.

\footnotetext{
${ }^{8}$ ASSIS, Carlos Augusto de. LOPES, João Batista. Tutela Provisória: tutela antecipada; tutela cautelar; tutela de evidência; tutela inibitória antecipada. Brasília: Gazeta Jurídica, 2018. p. 142.
} 
Tornou-se comum, quase uma regra em alguns tipos de ações, que a petição inicial viesse acompanhada do pedido de tutela provisória satisfativa. Logo, uma das primeiras discussões da lide já é a redistribuição do ônus do tempo do processo. O CPC/2015 já prevê que tal pedido pode ser, inclusive, antecedente a peça exordial.

Não há nada de errado em tal prática. Inclusive, faz sentido que uma das primeiras discussões na lide seja quem deverá arcar com o ônus do tempo do processo. Ocorre que este costume não pode ser considerada uma regra. Além da tutela provisória antecedente, ou aquela que acompanha a petição inicial, é plenamente possível um pedido incidental do mesmo.

É factível que a situação se altere ou que com a produção probatória a probabilidade do direito da parte cresça. Assim como quaisquer outros motivos que justifiquem que o pedido venha após a petição inicial. Deste modo, deve restar claro que não existe limitação temporal ou procedimental para a realização do pedido. Sendo ônus da parte apenas preencher os requisitos legais.

\section{DOS RECURSOS}

De início, percebe-se que a existência de recursos decorre de uma tentativa de atender a natural insatisfação do consumidor dos serviços jurisdicionais com eventual decisão desfavorável. Ainda que seja indispensável criar limites para o pleito recursal, sob pena de processos eternos, a simples erradicação dos recursos criaria um desagrado geral na população jurisdicionada.

Aliada a essa circunstância, existe o imperativo de impedir eventuais erros dos servidores encarregados dos atos judiciais. A atuação em massa do poder judiciário torna improvável o acerto em $100 \%$ das questões. Além de eventuais equívocos, denote-se a necessidade de se alinhar os entendimentos jurisprudenciais. ${ }^{9}$ Necessidade esta que apenas se reforçou com o CPC/2015.

Ademais, além de suas utilidades práticas, os recursos decorrem de previsão constitucional, mais precisamente, o art. 5으, LV, da carta de 1988. Pelos motivos já expostos, o constituinte fez por bem em prever a possibilidade de revisão.

DO CONCEITO DE RECURSO

Antes de adentrarmos na análise dos efeitos do recurso, em especial o efeito

9 JORGE, Flávio Cheim. Teoria Geral dos Recursos Cíveis [livro eletrônico]. 3. ed. São Paulo; Revista dos Tribunais, 2017. Item 3. 
suspensivo e o chamado efeito antecipativo, necessário se dedicar algumas linhas quanto a própria natureza jurídica dos recursos. Como se sabe, o propósito destes é uma alteração, ainda que busque meramente esclarecer, da decisão judicial.

Duas principais correntes se formaram quanto ao tema. Uma define o recurso como uma ação constitutiva autônoma, outra como a continuação do direito de ação. A primeira argumenta que haveria uma diferença primordial entre o objetivo do recurso, o qual seria impugnar uma decisão judicial, e da ação originária, a qual buscava um provimento jurisdicional outro.

A segunda, majoritária, aponta que o recurso seria uma continuidade do direito de ação. Ao atender o ônus processual de interpor o recurso, a parte estaria renovando o procedimento, continuando o pleito que já estaria formado quando da proposição originária. Como se estaria dando continuidade o direito de ação, os próprios requisitos do recurso espelham os requisitos para a proposição da ação.

A corrente majoritária, adotada, entre muitos, por Nelson Nery Jr. ${ }^{10}$, é a que adotamos neste trabalho. Estabelecido a natureza do instituto, passaremos a tratar de seus efeitos.

\section{DOS EFEITOS DOS RECURSOS}

Definido o que vem a ser um recurso, necessário se estabelecer o que vem a ser os chamados efeitos dos recursos. Estes efeitos são reflexos da interposição da figura recursal. Consequências naturais do exercício deste ônus. Em geral, são mais conhecidos os efeitos devolutivo e suspensivo.

A estes, Nelson Nery Jr. ${ }^{11}$ acrescenta os chamados efeito expansivo, efeito translativo e efeito substitutivo. Barbosa Moreira ${ }^{12}$ faz referência aos efeitos devolutivo, suspensivo, extensivo subjetivo e o impedimento ao trânsito em julgado. Flavio Cheim Jorge, por sua vez, aponta que haveria apenas um único efeito dos recursos, o denominado efeito devolutivo, sendo os demais decorrentes do efeito devolutivo, ou não seriam decorrentes da ação de interpor um recurso. Nas palavras do autor:

O primeiro efeito, denominado de devolutivo, não obstante a impropriedade do nome (como se analisará nos itens subsequentes), é o único que genuinamente poderia ser considerado efeito do recurso, já que corresponde, em qualidade e quantidade, àquilo que constitui o objeto e razão de ser dos recursos. Assim, quando se interpõe o recurso, realmente há uma transferência, por intermédio deste ato processual, de determinado objeto que será reavaliado e reanalisado pelo Judiciário.

\footnotetext{
${ }^{10}$ NERY JR., Nelson. Teoria Geral dos Recursos. 7 ed. São Paulo: Revista dos Tribunais, 2014. p. 223.

${ }_{11}$ NERY JR., Nelson. Teoria Geral dos Recursos. 7 ed. São Paulo: Revista dos Tribunais, 2014. p. 400

12 MOREIRA, José Carlos Barbosa. O Novo Processo Civil Brasileiro. 28 ed. Rio de Janeiro: Forense, 2010. p. $122-$ 123.
} 
Portanto, há relação de causa e efeito entre o recurso e a devolução da matéria. ${ }^{13}$

Luís Henrique Barbante Franzé14 ${ }^{14}$ classifica os efeitos dos recursos em independentes, os quais ocorrem pela simples interposição (devolutivo, translativo, expansivo, substitutivo e suspensivo), e os dependentes, os quais dependeriam de pedido da parte o preenchimento de requisitos legais (suspensivo dependente e antecipativo).

Os dependentes, nas palavras do autor, surgem "quando o efeito não é natural(não é gerado pela recorribilidade)". A problemática dessa classificação apresenta-se aí, na parte em que se admite efeito não gerado pela recorribilidade.

Percebe-se pela classificação acima citada, a concessão de efeito suspensivo que não fosse um dos casos já previstos no CPC, como o art. 1.012, e de antecipação de tutela seriam efeitos dos recursos, dependentes do preenchimento dos requerimentos legais.

Neste trabalho, adotaremos a classificação de Nelson Nery Jr., aceitando o amplo cabimento da concessão de tutela antecipada não como efeito dos recursos, mas sim como decorrência natural do poder jurisdicional, assim como previsto no art. 932, II, do CPC/2015.

\section{DO EFEITO SUSPENSIVO ATIVO}

Como exposto acima, os dois principais efeitos dos recursos são o devolutivo e o suspensivo. O devolutivo se desenvolve com o retorno da discussão da matéria ao judiciário. O efeito suspensivo impede que a decisão recorrida produza efeitos práticos. O efeito suspensivo pode ser decorrente de previsão legal, no caso em que a interposição do recurso irá dar continuidade a uma suspensão que já existia. Ou pode ser determinado pelo juízo.

Na égide do CPC/1973, apenas havia previsões de concessão de efeito suspensivo ope judicis em certos recursos, não restando claro a possibilidade de concessão de tutela antecipada na fase recursal. Tendo em vista esta lacuna legal, a doutrina começou a falar do efeito suspensivo ativo.

Tal efeito seria a suspensão de uma decisão negativa. A decisão positiva, ainda que seja meramente declaratória, altera a relação jurídica discutida. A mesma deverá ter um comando, colocando o polo ativo em posição privilegiada em desfavor do polo passivo. O mais importante é a efetiva mudança no mundo jurídico, a qual pode vir seguida de consequências na realidade fática.

Por sua vez, a decisão negativa mantém um cenário já estabelecido, inovando ao julgar improcedente o pleito do autor. A situação contra a qual o pleiteante se insurgiu permanece. Por conseguinte, não se altera o mundo fático. Ao suspender uma decisão negativa, se criaria

\footnotetext{
13 JORGE, Flávio Cheim. Teoria Geral dos Recursos Cíveis [livro eletrônico]. 3. ed. São Paulo; Revista dos Tribunais, 2017. Item 11.2.

${ }^{14}$ FRANZÉ, Luís Henrique Barbante. Tutela Antecipada Recursal. 4. ed. Curitiba: Juruá, 2014. p. 134.
} 
um efeito ativo, concedendo o bem de vida requerido pela parte.

Como será tratado abaixo, não há necessidade de falar de efeito suspensivo ativo, uma vez que o CPC/2015 claramente trata da possibilidade de tutela provisória na fase recursal.

\title{
DA CONCESSÃO DE TUTELA PROVISÓRIA SATISFATIVA NOS RECURSOS
}

O uso do Direito Processual Civil não deve ser guiado por uma visão que esqueça a correlação desta com outras matérias do direito. Apesar de ser um ramo independente, o processo não é uma ilha, um ser inteiro em si próprio, está conectado com os outros ramos da ciência jurídica e é afetado por estes. Sobretudo, o direito constitucional.

Tal visão se traduz no chamado modelo constitucional do direito processual civil. Este é o norte que orienta a hermenêutica e a aplicação do processo.

A interpretação dos institutos de direito processual civil, de forma a satisfazer o modelo constitucional do processo, não se resolve como uma mera aplicação dos princípios constitucionais em casos concretos. O que se requer é a concretização do disposto na Lei Maior no âmbito do processo civil, principalmente quando as previsões infraconstitucionais que o regulam não estejam perfeitamente de acordo. Sobre o tema Cassio Scarpinella Bueno fala:

\begin{abstract}
Estudar o direito processual civil na e da Constituição, contudo, não pode ser entendido como algo passivo, que se limita à identificação de que determinados assuntos respeitantes ao direito processual civil são previstos e regulamentados naquela Carta. Muito mais do que isso, a importância da aceitação daquela proposta metodológica mostra toda sua plenitude no sentido ativo de aplicar as diretrizes constitucionais na construção do direito processual civil, realizando pelo e no processo, isto é, pelo e no exercício da função jurisdicional, os misteres constitucionais reservados para o Estado brasileiro, de acordo com o seu modelo político, e para seus cidadãos. (Grifos no Original) $)^{15}$
\end{abstract}

Deste modo, o processo civil deve ser estudado a partir da Lei Maior para apenas depois se chegar à legislação infraconstitucional, em especial o $\mathrm{CPC}^{16}$. Assim, busca-se nestas leis institutos aptos a concretizar os comandos constitucionais e não se aceita que a mera insuficiência de trato pelo legislador obste a plena eficácia da carta magna ${ }^{17}$.

A previsão do art. 5ํ, XXXV, da Lei Maior não comporta uma interpretação restritiva, sendo imperativo que o Poder Judiciário promova não apenas o acesso a jurisdição, o direito de ação, mas também que esta seja adequada, efetiva. De outro modo, a norma constitucional

\footnotetext{
15 BUENO, Cassio Scappinella. O “Modelo Constitucional do Direito Processual Civil”: Um Paradigma Necessário de Estudo do Direito Processual Civil e Algumas de suas Aplicações. Revista de Processo, v. 161, p. 261, jul. 2008.

16 LOPES, João Batista. Tutela Antecipada no Processo Civil Brasileiro. 4. ed. São Paulo: Revista dos Tribunais, 2009. p. 27.

${ }^{17}$ MARINONI, Luiz Guilherme. Tutela de Urgência e Tutela da Eivdência. 2 ed. São Paulo: Revista dos Tribunais, 2018. p. 24.
} 
seria letra morta, sem utilidade no mundo prático. Quanto a essa interpretação:

\begin{abstract}
Pelo princípio constitucional do direito de ação, além do direito ao processo justo, todos têm o direito de obter do Poder Judiciário a tutela jurisdicional adequada. Não é o suficiente o direito à tutela jurisdicional. É preciso que essa tutela seja a adequada, sem o que estaria vazio de sentido o princípio. Quando a tutela adequada para o jurisdicionado for medida urgente, o juiz, preenchidos os requisitos legais, tem de concedê-la, independentemente de haver lei autorizando, ou, ainda, que haja lei proibindo a tutela urgente. (Grifos no Original) ${ }^{18}$
\end{abstract}

Portanto, é direito constitucional da parte um processo devido garantindo-se todos os instrumentos para tanto. Percebe-se que não há óbice, mas sim incumbência do sistema em garantir a efetividade do processo mesmo na fase recursal.

Ademais, ao monopolizar o uso da força, impossibilitando que os cidadãos resolvam disputas diretamente, o Estado assume o ônus de garantir soluções adequadas para eventuais conflitos. Imprescindível que o processo judicial seja justo e efetivo, sob pena de a própria razão de ser do Estado se perca.

O CPC/2015 avançou nas previsões de seu antecessor no que se refere a possibilidade da concessão de tutela provisória na fase recursal, havendo previsão expressa no art. 932, II. Ainda que meramente cite a possibilidade da concessão na fase recursal, percebe-se que os demais requisitos já estão delineados nos arts. 294 e ss..

Mesmo na ausência de normas legais, a plena aplicação do direito fundamental previsto no inciso XXXV já seria o suficiente. Como se sabe, os direitos fundamentais tem aplicação imediata, não necessitando de outras normas para sua aplicabilidade na vida prática.

Deste modo, o art. 932 deve ser lido em conjunto com os demais dispositivos que tratam das tutelas provisórias, buscando a maior efetividade possível do processo civil. Obviamente, que todos os requisitos legais ainda devem ser seguidos, devidamente adaptados para esta fase processual.

Citemos ainda a previsão do art. 995, p. ún., o qual afirma que "A eficácia da decisão recorrida poderá ser suspensa por decisão do relator, se da imediata produção de seus efeitos houver risco de dano grave, de difícil ou impossível reparação, e ficar demonstrada a probabilidade de provimento do recurso."

A interpretação deste artigo não deve ser que a possibilidade de concessão de tutela antecipada, durante o procedimento recursal, se limita a concessão de efeito suspensivo ${ }^{1920}$.

\footnotetext{
${ }_{18}$ NERY JÚNIOR, Nelson. Princípios do Processo na Constituição Federal. 9. ed. São Paulo: Revista dos Tribunais. 2009. p. 172

${ }^{19}$ ASSIS, Carlos Augusto de. LOPES, João Batista. Tutela Provisória: tutela antecipada; tutela cautelar; tutela de evidência; tutela inibitória antecipada. Brasília: Gazeta Jurídica, 2018. P. 148.

${ }^{20}$ WAMBIER, Teresa Arruda Alvim. CONCEIÇÃO, Maria Lúcia Lins. RIBEIRO, Leonardo Ferres da Siva. MELLO, Rogerio Licastro Torres de. Primeiros Comentários ao novo código de processo civil: artigo por artigo/coordenação Teresa Arruda Alvim Wambier. São Paulo: Editora Revista dos Tribunais, 2016.p. 1581.
} 
Como já apontado acima, o direito das partes a um procedimento efetivo se impõe, devendo a interpretação do sistema processual buscar esse fim.

Ademais, o art. 932, II, trata claramente de tutela provisória nos moldes do Livro $\mathrm{V}$ da Parte Geral do CPC ${ }^{21}$. Deste modo, resta claro que a codificação processual vigente previu claramente a tutela provisória no âmbito recursal, sem limitações.

\title{
DO PROCEDIMENTO
}

No que se refere a questão procedimental, ela em muito se assemelha a tutela provisória em primeiro grau. Os requisitos de concessão, em regra são os mesmos. Obviamente que com a existência de decisão prévia sob a matéria, deverá haver uma cautela maior do relator quanto o preenchimento dos requisitos da concessão de tutela provisória.

Douglas Dal Monte, em palestra realizada no dia 25 de julho de 2019 no II Congresso Brasileiro de Processo Civil, faz a comparação com um funil invertido, quanto mais se sobe nas instâncias, mais difícil ficaria a concessão da tutela provisória.

Concordamos com o douto palestrante. A análise do caso já realizado pela instância inferior deve ser levada em conta pelo relator na fase recursal. Obviamente que não existe, ou deve existir, qualquer tipo de vinculação a decisão do juízo a quo. Sobre a autonomia da instância revisora, citemos a doutrina:

\begin{abstract}
Por tais motivos, não se pode vincular de forma tão drástica o que foi decido pelo juízo a quo, a ponto de, só por isto, impedir a análise da verossimilhança da alegação e da presença de prova inequívoca, até porque, repetimos, esta mesma avaliação ocorre para a concessão do efeito suspensivo, só que, quanto a este, não há dúvidas, pois a literalidade do disposto no artigo 558 assim determina. ${ }^{22}$
\end{abstract}

Deste modo, o pedido de tutela provisória deve ser analisado na fase recursal seguindo os mesmos requisitos da primeira instância, uma vez que não há momento prédefinido para o pedido de tutela provisória ${ }^{23}$.

\section{DO PEDIDO EM CONTRARRAZÕES}

As considerações postas nos itens acima serviram para que definíssemos as seguintes questões: A tutela antecipada, ou tutela provisória satisfativa, busca redistribuir o ônus do tempo do processo. A legitimidade para o pedido de tutela antecipada dentro da lide não é limitada ao polo ativo, mas sim ao interesse da parte. O momento do pedido não é limitado a apresentação inicial do pedido, sendo perfeitamente possível que o preenchimento dos

\footnotetext{
${ }^{21}$ BUENO, Cassio Scarpinella. Comentários ao código de processo civil - volume 4/Cassio Scarpinella Bueno (coordenador). São Paulo: Saraiva, 2017. p. 62.

${ }^{22}$ FERREIRA, William Santos. Tutela Antecipada no Âmbito Recursal. São Paulo: Revista dos Tribunais, 2000. p. 292.

${ }^{23}$ LOPES, João Batista. Tutela Antecipada. 5ạ ed. São Paulo: Castro Lopes, 2016. p. 199.
} 
requisitos ocorra posteriormente. E, o CPC/2015 previu expressamente a possibilidade de concessão de tutela provisória no âmbito recursal.

Partindo-se de tais premissas, analisemos a questão central do presente trabalho. A possibilidade de se requerer uma tutela provisória, chamado antes o efeito suspensivo ativo, no âmbito das contrarrazões a um recurso.

Em regra, a parte que tem o ônus de apresentar contrarrazões se encontra em uma posição privilegiada, uma vez que é do interesse da outra parte impugnar uma decisão que lhe foi desfavorável. Em termos leigos, a parte no polo passivo do recurso, na maioria dos casos, está "vencendo". Imagina-se que em uma situação desta, a parte está confortável com o ônus do tempo do processo, sendo que pode lhe ser até favorável uma demora maior.

Ocorre que isto não é necessariamente verdade. Imagine-se o caso de um pleito julgado procedente pelo juízo de primeiro grau. É interposta a apelação pela parte sucumbente, e a mesma tem efeito suspensivo. Concomitantemente, há uma alteração na situação fática, criando a necessidade para o recorrido de ter acesso imediato ao bem de vida discutido na lide.

Tal cenário não é difícil de se imaginar. A necessidade da parte, ou a possibilidade que o bem se perca, podem facilmente se alterar na realidade fática, tornando imprescindível um provimento jurisdicional. Como já se expôs acima, o monopólio do emprego da força pelo Estado o obriga a oferecer meios de garantir o direito das partes, e não apenas conceder eventual indenização.

Nestes moldes, não há como se falar de falta de interesse de agir apenas porque a parte passou para o polo passivo na fase recursal. Sendo preenchidos os requisitos legais, a concessão da tutela provisória é medida que se impõe. No mesmo sentido:

\footnotetext{
Este estado suspensivo, como já tratado no comentário específico, ocorre mesmo antes da interposição do recurso - com este, o estado suspensivo prolonga-se até o julgamento da apelação.

Diante deste quadro, situações podem surgir que possibilitem a postulação da tutela antecipada no âmbito recursal. Na tutela antecipada há a antecipação dos efeitos do provimento definitivo, o que pode ser deferido antes da sentença.

O que abre as portas para o acesso à tutela antecipada é justamente a ausência de efeitos da tutela de conhecimento. [...] O que se busca é o bem de vida almejado; enquanto este não for entregue, o pedido de tutela antecipada é cabivel.

A sentença com efeitos suspensos nada mais é do que um provimento sem eficácia, tal qual ocorria mesmo antes de existir. Como antes poderia ser deferida a tutela, é intuitivo que poderá também ser deferido após a existência de sentença... ${ }^{24}$
}

Não há como se falar de devido processo legal, processo efetivo ou modelo constitucional do processo se é permitido a direitos perecerem no dia-a-dia do fórum. Ainda que incomum, não há como se afastar o uso da tutela provisória nas contrarrazões se há

\footnotetext{
${ }^{24}$ FERREIRA, William Santos. Tutela Antecipada no Âmbito Recursal. São Paulo: Revista dos Tribunais, 2000. p. 306307.
} 
interesse da parte. A busca por efetividade apenas pode encontrar limites dentro dos próprios direitos constitucionais ou em caso de uma impossibilidade fática.

Todavia, necessário apontar que não se trata de matéria pacífica, havendo decisões judiciais em contrário. Citemos uma do TJMG:

EMENTA: APELAÇÃO CÍVEL - COBRANÇA - INDENIZAÇÃO - CONTRATO DE SEGURO DE VEÍCULO - INDENIZAÇÃO SECURITÁRIA - PAGAMENTO NEGADO - PRELIMINAR DE NÃO CONHECIMENTO DO RECURSO - ANTECIPAÇÃO DE TUTELA NAS CONTRARRAZÕES IMPOSSIBILIDADE - FURTO DO BEM - MÁ-FÉ DO SEGURADO NÃO DEMONSTRADA DESCUMPRIMENTO CONTRATUAL - OCORRÊNCIA COBERTURA DO SEGURO DEVIDA LUCROS CESSANTES - COMPROVADOS. (...). As contrarrazões qualificam-se processualmente como veículo de resistência à pretensão recursal, não se revelando apropriadas para incorporar pedido de antecipação da tutela recursal... ${ }^{25}$ (Grifos Nossos)

O posicionamento do Tribunal Mineiro parte do pressuposto que as contrarrazões seriam limitadas a uma matéria de resistência, uma situação meramente passiva. Como já discorremos acima, tal posicionamento não coaduna com a legislação processualista vigente ou com o modelo constitucional do processo. O fato de as contrarrazões serem principalmente uma peça defensiva não as limita a tanto.

Caso comprovado uma ameaça ao direito da parte, requerendo uma tutela provisória, seja satisfativa ou cautelar, a parte estaria impossibilitada de realizar qualquer pedido? A decisão judicial, assim como seu voto, não deixa claro se a problemática seria na peça escolhida ou na possibilidade de o polo passivo realizar tal requerimento.

Sendo uma questão meramente formal, ou seja, o pedido estar em contrarrazões e não em uma petição outra, não podemos concordar com o posicionamento. O princípio da instrumentalidade das formas, preconizado no art. 188 do CPC/2015, exige o aproveitamento dos atos realizados pelas partes. Permitir que o bem de vida discutido pode ser colocado em risco por mera questão formal viola a garantia do devido processo legal.

Todavia, se a questão decorre da posição do jurisdicionado, no polo passivo da lide, trata-se de violação ainda maior às garantias constitucionais de um processo devido e efetivo. A interpretação realizada acaba por negar ao recorrido uma proteção mínima a uma tutela específica. Nestes moldes, retorna-se ao tempo em que o consumidor de serviços jurisdicionais deveria se satisfazer com eventual indenização e não com o bem de vida que faz jus, independente de ser vitorioso ou não ao final da lide.

Portanto, não podemos coadunar com o posicionamento acima citado, assim como outros $^{26}$. Sendo preenchidos os requisitos legais, a concessão da tutela provisória é medida que

\footnotetext{
25 TJMG - Apelação Cível 1.0024.12.344169-3/001, Relator(a): Des.(a) Mônica Libânio , 11ạ CÂMARA CíVEL, julgamento em 13/12/2017, publicação da súmula em 18/12/2017.

${ }^{26}$ TJDF; APO n. 20140111522012; 6a turma cível; Julgamento: 04.11.2015; Relator(a): Ana Maria Duarte Amarante Brito; Publicado no DJE: 10.11.2015, pág. 341.
} 
se impõe, por se tratar de direito da parte, não havendo discricionariedade por parte do Estadojuiz ${ }^{27}$.

Obviamente que a existência de decisão favorável do juízo a quo não afasta a necessidade de cumprimento dos requisitos legais para a concessão da tutela antecipada. Como exposto acima, não há vinculação do juízo ad quem ao juízo a quo. Ademais, ainda que se deva respeitar o trabalho realizado pela instância inferior, deve-se lembrar que a opção do legislador foi de incidência do efeito suspensivo nestes casos. Portanto, o afastamento deste efeito apenas deve ocorrer se preenchidos os requisitos legais.

Deste modo, é plenamente cabível que a parte recorrida, quando da oferta de contrarrazões, ou ainda em momento posterior, requeira a tutela antecipada, atendendo os mesmos requisitos para a concessão em outra fase do processo.

\section{CONCLUSÕES}

O devido processo legal, para que possa ser chamado de "devido", não deve apenas ser justo, exige-se que atenda o anseio democrático por uma justiça eficaz. Quando o estado monopoliza o uso da força e determina que os conflitos entre os cidadãos deverão ser resolvidos dentro dos limites legais, ele cria para si a obrigação de oferecer meios para se garantir que as partes tenham acesso a seus direitos.

Uma das ferramentas criadas para buscar a eficácia do processo foi a tutela antecipada. Entretanto, a prática forense acabou limitando a análise e pedido deste instituto ao início da lide. Ocorre que a necessidade, ou o preenchimento dos requisitos legais, pode perfeitamente se apresentar apenas na fase recursal, não havendo nenhum impedimento para sua concessão dentro da ordem legal estabelecida pelo CPC/15.

Os recursos são uma fase do processo, não se caracterizando um processo autônomo. Logo, ferramentas como a tutela provisória podem ser acessadas dentro desta fase, tendo em vista que inexiste limitação temporal ou procedimental para tanto.

Além de não haver esta limitação pelo momento, também não há quanto em relação as partes. Se partimos do pressuposto que o pedido é possível para o recorrente, o qual é o sucumbente na decisão recorrida, não há razão lógica para se criar uma limitação ao recorrido.

A paridade das armas que deve ser respeitada dentro do processo civil não pode tolerar que um instituto como a tutela provisória satisfativa seja exclusiva de um dos polos do processo, sendo necessário que ambos tenham acesso a mesma, contanto que preencham os requisitos definidos na norma.

${ }^{27}$ LOPES, João Batista. Reflexões sobre a pretendida discricionariedade judicial. Revista de Processo, v. 274 , dez. 2017. 
Reconhecemos que o tema ainda não foi devidamente aceito pela jurisprudência, todavia, devemos discordar da solução apresentada pelo Tribunal retro citado. Conforme exposto pela doutrina, não deve haver limitações para o direito das partes de pedir a tutela provisória, mesmo que no polo passivo.

O modelo constitucional do processo exige que a eficácia do processo seja protegida, não sendo suportada interpretações limitadoras. O fato de a parte se encontrar no polo passivo, o que pode mudar em uma nova fase, não deve ser limite para a proteção do bem da vida.

Deste modo, cabe ao recorrido se desincumbir do ônus de comprovar o preenchimento dos requisitos legais. O fazendo, há o direito a concessão de tutela antecipada de acordo com a legislação processual vigente.

\section{REFERÊNCIAS}

ASSIS, Carlos Augusto de. LOPES, João Batista. Tutela Provisória: tutela antecipada; tutela cautelar; tutela de evidência; tutela inibitória antecipada. Brasília: Gazeta Jurídica, 2018.

BUENO, Cassio Scarpinella. Comentários ao código de processo civil - volume 4/Cassio Scarpinella Bueno (coordenador). São Paulo: Saraiva, 2017.

BUENO, Cassio Scarpinella. O "Modelo Constitucional do Direito Processual Civil": Um Paradigma Necessário de Estudo do Direito Processual Civil e Algumas de suas Aplicações. Revista de Processo, v. 161, p. 261, jul. 2008.

FERREIRA, William Santos. Tutela Antecipada no Âmbito Recursal. São Paulo: Revista dos Tribunais, 2000.

FRANZÉ, Luís Henrique Barbante. Tutela Antecipada Recursal. 4. ed. Curitiba: Juruá, 2014. GRINOVER, Ada Pellegrini. O Controle de Políticas Públicas pelo Judiciário. Revista de Processo. v. 164, p. 9, out. 2008.

JORGE, Flávio Cheim. Teoria Geral dos Recursos Cíveis [livro eletrônico]. 3. ed. São Paulo; Revista dos Tribunais, 2017.

LOPES, João Batista. Tutela Antecipada. 5ạ ed. São Paulo: Castro Lopes, 2016.

LOPES, João Batista. Tutela Antecipada no Processo Civil Brasileiro. 4. ed. São Paulo: Revista dos Tribunais, 2009.

MALATESTA, Nicola Framarino dei. A lógica das provas em matéria criminal. Vol. I. São Paulo: Saraiva, 1960.

MARINONI, Luiz Guilherme. Tutela de Urgência e Tutela da Eivdência. 2 ed. São Paulo: Revista 
dos Tribunais, 2018.

MENDES, Gilmar Ferreira. BRANCO, Paulo Gustavo Gonet. Curso de Direito Consitucional. 6. ed. São Paulo: Saraiva, 2011. p. 256.

MOREIRA, José Carlos Barbosa. O Novo Processo Civil Brasileiro. 28 ed. Rio de Janeiro:

Forense, 2010.

NERY JÚNIOR, Nelson. Princípios do Processo na Constituição Federal. 9. ed. São Paulo:

Revista dos Tribunais. 2009.

NERY JÚNIOR, Nelson. Teoria Geral dos Recursos. 7 ed. São Paulo: Revista dos Tribunais, 2014.

WAMBIER, Teresa Arruda Alvim. CONCEIÇÃO, Maria Lúcia Lins. RIBEIRO, Leonardo Ferres da Siva. MELLO, Rogerio Licastro Torres de. Primeiros Comentários ao novo código de processo civil: artigo por artigo/coordenação Teresa Arruda Alvim Wambier. São Paulo: Editora Revista dos Tribunais, 2016.

ZAVASCKY, Teori Albino. Antecipação da Tutela. São Paulo: Saraiva, 1997. 